\title{
Employing Resilience in the United States Forest Service
}

\section{Abstract}

3

4

5

6

The concept of resilience has permeated the discourse of many land use and environmental agencies inan attempt to articulate how to develop and implement policies concerned with the social and ecological dimensions of natural disturbances. Several distinct definitions of resilienceexist, each with its own concepts, focus and contexts related to land use policy and management. This often makes understanding the inherent objectives of policies and related principles challenging. The United States Forest Service (USFS) is one example where ambiguity and uncertainty surrounding the use of resilience permeates the content of documents in various areas of the agency. The objective of this paper is to investigate how the USFS employs the term resilience as a means to communicate strategies for managing forest lands. We perform a content analysis of 121 USFS documents including budgetary justification reports, research findings (i.e. journal articles, book chapters and technical reports), public releases and newsletters to analyze both the rise and specific use of the term resilience in the USFS. Our analysis, which is guided by definitions of resilience in the social-ecological systems literature, reveals that the ambiguity surrounding the use of resilience in the academic literature is reflected in the content of USFS documents. However, we also find that often criticized versions of resilience (namely engineering resilience) are minimally employed by the USFS, and instead the agency focuses on the notion of ecological resilience in which natural disturbances are seen as an important component of the landscape. In some cases, the USFS employs notions of socialecological resilience, however, the extent to which specific components of social-ecological resilience are integrated into management strategies appears minimal. The findings from this study suggest that clarity regarding the type and function of resilience needs to improve in USFS 
24 documents, and that the agency should evaluate the existing question in the SES literature of

25 resilience of what to what?

26

27 Keywords: Resilience, United States Forest Service, landscapes, communities, content analysis. 


\section{Employing Resilience in the United States Forest Service}

"The bottom line is this: We need to restore the resilience of America's forests and grasslands to disturbances of all kinds. The treatments needed will improve watershed health, increase water quantity, improve water quality, generate rural prosperity, and meet our shared vision of healthy, resilient landscapes. Those are our priorities."

Presenting to the Western States Land Commissioners Association, January 13, 2010

(Tidwell2010c)

\section{Introduction}

The opening quote to this paper is taken from the President of the United States' budget

39 request for fiscal year 2015 identifying the Administration's top priorities for the United States'

40 Forest Service (USFS).The quote speaks to a desire by the USFS to protect the nation's forests

41 against threats of disturbance that compromise ecosystem health and social wellbeing. Central to

42 this quote is the use of "resilience," a term that is increasingly employed in the discourses of

43 public agencies to describe land use policies and management strategies aimed at preparing for,

44 or dealing with, natural and human-caused disturbances (Ostrom and Janssen 2005). While the

45 use of resilience with respect to forests provides a perceived direction for the USFS to take when

46 developing and implementing policies, ambiguity surrounding the use of the term resilience in

47 the context of environmental policies and management leaves the meaning of this quote open for

48 interpretation. Resilience has been used to describe land managementobjectives that promote the 49 capacity to adapt to disturbance (Nelson et al. 2007) and, conversely, has also been employed to 
50 describe the objective of minimizing the potential and influence of disturbance on a system

51 (Tilman and Downing 1996). The former requires perceiving resilience as the ability to modify

52 practices and behaviors when faced with disturbance in ways that help maintain important

53 components of a system (Walker et al. 2004), while the goal of the latter isto manage landscapes

54 in a mannerthat minimizes the impact of disturbance, thus also minimizing the time it takes to

55 return the landscape to its pre-disturbance state (Holling 1996). Multiple critiques of the use of

56 resilience have emerged in various disciplines such as disaster planning (Manyena 2006) and

57 urban development (MacKinnon and Derickson 2013).Yet, there are several signals

58 demonstrating the growing, or at least continued interest in investigating the use of the concept

59 of resilience for developing policies pertaining to, amongst other things, land use. Such signals

60 include the recent emergence of the journal Resilience: International Policies, Practices and

61 Discourses, which focuses on critical social theorizing of resilience in numerous contexts; the

62 rise in the use of the term in the land use policy literature (e.g. Adger et al. 2011, Schouten et al.

63 2012, Lloyd et al. 2013, Ogden et al. 2013, Wilson 2013); and the current evaluation by the US

64 Congress of the Resilient Forests Act of 2015 (H.R.2647).

65 The concept of resilience as a main USFS priority invites questions regarding how

66 resilience is perceived, implemented and achieved in the context of agency goals and land use

67 change. Federal agencies, especially in the United States, are typically large organizations

68 governed through hierarchical structures composed of many geographically separated

69 departments and individuals, and so the way in which resilience is perceived can have significant

70 implications for policy implementation. The USFS, for example, is responsible for the

71 management of over 193 million acres of federal land across 154 individual national forests and

72 grasslands in all regions of the United States (USFS 2015). The bureaucracy is multi-level, with 
73 each level of the hierarchy given some discretion in forest management priorities and practices.

74 The Chief of the Forest Service oversees: (1) the national forest system, which is responsible for

75 the management of the national forests and grasslands, (2) research and development, (3) state

76 and private forestry, and (4) administration program and legislation, each of which isguided by a

77 deputy chief and programmatic staff in the National Office. Below the chief are regional

78 foresters and regional program staffs for nine administrative regions, 119 forest supervisors and

79 supporting office program staff and 635 ranger districts with accompanying district program

80 staff.

81 The structure of the USFS and other federal agencies can affect how policies are realized

82 on the ground. Federal policies are rarely adopted or implemented quickly in a homogenous

83 fashion (Moseley and Charnley 2014), but the ways in which certain terms or phrases are used in

84 agency documents shapes the direction of institutional change over time. The use of specific

85 terminology frames policy discussions by legitimizing and delegitimizing institutional

86 arrangements (Hajer 1995) and shapes resource management guidance in the form of rules,

87 regulations, policies, and budgeting and accountability procedures. This is especially true in an

88 agency such as the USFS in which policy implementation can vary from one region to another

89 based on the beliefs of individual bureaucrats, the pressure exerted from higher levels in the

90 organization, and the amount of collaboration that takes place between individuals (Moseley and

91 Charnley 2014). Investigating how the use of resilience impacts federal agencies such as the

92 USFS requiresdetermining what resilience really means when referring to specific forests and

93 their resources, what components of the social and ecological systems to include in resilience

94 approaches for managing forests, and, ultimately, how to breed resilience into forests under the

95 presence and uncertainty of climate change (Park et al. 2011). Additionally, taking a resilience- 
96 based land use management approachrequires that land managers address the question put forth

97 by Carpenter et al. (2001):resilience of what to what? This question asks one to define the

98 component or state of the system that is vulnerable (of what?), and the type of disturbance that is

99 under investigation (to what?). From a forest management perspective, one could consider the

100 state of a productive forest being resilient to a natural disturbance such as wildfire, insect

101 outbreaks or invasive species. Managing for resilience would then require altering practices to

102 achieve specific objectives that are dependent on how resilience is defined. For example, if one

103 defines resilience as having the forest rebound as quickly as possible from disturbance, then

104 increasing disturbance suppression efforts may be desired. Conversely, if resilience were viewed

105 as having disturbance be part of a healthy forest, then management activities could examine

106 potential forest composition that permits disturbance to take place without significantly altering

107 the state of the forest (a more detailed explanation of resilience perspectives is provided in the

108 next section).

109 The objective of this paper is to investigate how the USFS is employing the use of

110 resilience and associated termsin agency communications related to land management. We

111 perform a content analysis of public digital documents from the USFS to understand how these

112 terms are utilized to articulate agency mission, agendas, and developing strategies towards the

113 management of public forestlands. In doing so, we aim to understand how the use of specific

114 terms has been employed in the USFS discourse in the past decade, if their use has increased

115 over time (thus mirroring trends in the academic literature), and in what context these terms are

116 used. We turn to the literature on social-ecological systems (SES) to contextualize the uses and

117 interpretations of the term resilience. While numerous disciplinary definitions and approaches to

118 resilience exist, the SES literature provides a suitable theoretical framework for examining the 
119 use of resilience related to national forest land use policies because of the USFS' mission to

120 focus on both the ecological and social dimensions of forests. Our intent is not to use the SES

121 literature as a means to critique USFS policies, but instead to enhance our understanding of how

122 the agency is discussing these policies in their public documents. In the next section, we draw

123 distinction between three approaches to resilience as defined in the SES literature: (1)

124 engineering resilience, (2) ecological resilience or social resilience, and (3) social-ecological

125 resilience. Discussing the three definitions provides a conceptual spectrum on which to evaluate

126 how resilience is used in USFS documents. We then present the methods and results from the

127 content analysis, followed by a discussion that describes how the USFS has engaged in the

128 resilience discourse.

129

\section{Approaches to Resilience}

The earliest use of resilience in literature pertaining to either ecological or social systems

132 stems back to Holling (1961)who describedthe interactions of insect populations using ecological

133 stability theory. The term was later used by Holling (1973) to describe ecological systems as

134 complex entities with interacting parts that do not settle upon states of equilibrium. Since then,

135 resilience has been situated as a "perspective" (Folke 2006) and a way of "thinking" (Walker and

136 Salt 2006) when considering the sustainability of social and ecological systems. While different

137 interpretations of the relationship between sustainability and resilience exist, we look towards the

138 sustainability science literature that contextualizes "sustainability" as an umbrella concept

139 inclusive of "resilience". As Turner (2010) describes, sustainability science addresses social

140 systems relative to the functioning of the Earth system, while resilience provides a specific lens

141 to interrogate how social and natural systems collectively respond to disturbance by their 
142 capacity to self-organize, learn and adapt. One of the reasons the term resilience is increasingly

143 utilized is because much of the focus of late in the sustainability science literature has turned to

144 the consequences of human and natural disturbances. Therefore, resilience is not supplanting

145 sustainability; instead, its increase in use indicates a growing interest in using it to address issues 146 of sustainability.

147 This literature provides three distinctive understandings of resilience. The first 148 perspective of resilience views systems as if they exist in a single state of equilibrium where 149 inputs and outputs remain relatively constant over time. Resilience in this sense is measured by 150 how fast a system can recover to this state of equilibrium following disturbance. Defined by 151 Holling (1996) as engineering resilience, this approach has been the prevailing paradigm of 152 contemporary resource management in which resource flows are controlled and optimized (Folke 153 2006). The appealing nature of engineering resilience is that it can be quantified in terms of the 154 time interval between a disturbance event and the point at which the system is thought to have 155 recovered. While such quantifications are not void of subjective measurements, engineering 156 resilience maintains an end goal to which a system can be managed. That being said, the success 157 of engineering resilience relies upon system efficiency, which is typically achieved by 158 eliminating variability in ecosystem features and replacing it with "constancy of production" 159 (Holling 1996). This form of resiliencepresents ecosystems as linear, non-dynamic, and 160 predictable - elements that conflict with more nuanced perspectives of human and ecological 161 systems as linked, non-linear, dynamic, and riddled with uncertainty regarding how forests 162 change over time (Holling 1996). Managing forests for resistance to disturbance could, for 163 example, involve attempting to eliminate the likelihood that disturbance will occur, or, more 
164 commonly, attempting to remove disturbances from the landscape as quickly as possible to allow

165 the forest to return to a desired equilibrium state to maintain optimal outputs.

166 The second perspective of resilience in the SES literature focuses on the ability of an

167 ecosystem or social system to withstand disturbance while still maintaining necessary functions.

168 Rather than managing resources as single state systems in equilibrium, this form of resilience

169 acknowledges that systems have multiple potential states, and disturbance can push a system

170 through some threshold from one state into another. The inevitability of disturbance is handled

171 by building buffer mechanisms that allow essential function to persist while the system

172 experiences shocks and undergoes changes. Managing for persistence thus focuses efforts to

173 maintain some desired characteristics of a system while fluctuations take place in system

174 behaviors or the environment (Anderies et al. 2004).

175 In this light, the resilience of social systems can be described as the ability of

176 communities or collectives to cope with external shocks or stresses that result from social,

177 environmental, and social change (Adger 2000). Likewise, building resilience into ecological

178 systems requires that landscapes contain sufficient variability and redundancies to be able to

179 experience disturbance events without compromising important ecological processes and

180 characteristics. From a land use policy perspective, managing forests in this way places focus on

181 allowing for disturbance to occur while maintaining ecological or socially valuable resources.

182 This form of resistance is identified by Folke (2006) as either ecological resilience or social

183 resilience depending on the part of the system under focus.However, it should be noted that

184 ecological resilience and social resilience are not interchangeable merely by switching out an

185 ecological system for a social system. Resilience operates quite differently in either system, and

186 some have even argued that the resilience concept as borne from ecology is not altogether 
187 applicable in the social sciences (Olsson et al. 2015). Nevertheless, we utilize Folke's framework

188 for facilitating our analysis of the use of resilience in the USFS.

189 The third approach to resilience deals with the capacity of anintegrated social-ecological

190 system to adapt to disturbance (Smit and Wandel 2006). This perspective, termed socio-

191 ecological resilience, acknowledges that change in one part of the system drives reorganization

192 in system properties in space (e.g. tree seeds after fire) and function (e.g. wood products derived

193 from forests), and to form new combinations of actor relationships, both hierarchically (e.g.

194 relationships between governments) and horizontally (e.g. relationships between communities,

195 non-governmental actors, and other stakeholders). In their theory of panarchy,Gunderson and

196 Holling (2002) characterize this type of adaptive change, where change facilitates a

197 reorganization of a system's characteristics, and pathways for change can be guided to maintain

198 prior, existing, or desired functions. However, managing forests for change requires learning

199 about the interdependencies within and between social and ecological systems that exist across

200 multiple spatial and temporal scales. One of the defining features of panarchythat distinguishes

201 the social-ecological perspective from the others is that different elements of a system are

202 examined at the scales at which they occur, and how they impact processes at larger or smaller

203 scales (Cumming et al. 2013). For example, small changes at the federal congressional or agency

204 level could exert profound changes at a localized scale where forest management activities take

205 place. Conversely, localized disturbances such as wildfire occurring in multiple areas at the same

206 time could lead to a regional level shift in climatic processes such as carbon cycling. From a

207 temporal perspective, small events that take place over minutes or hours (e.g. insects killing a

208 tree) can alter the state of the system over much longer time periods (e.g. timeframe of forest

209 succession). While understanding the cross-scale drivers of change is challenging (a fact that 
210 may explain why this form of resilience receives less attention in the SES literature), it is critical

211 to understand these drivers because building adaptive capacity requires changes in system

212 behaviors that can reverberate through a system, potentially having unintended negative

213 consequences. As Folke (2006) states, not all forms of resilience are beneficial. Managing forests

214 for change requires understanding how social systems influence disturbance regimes, and in turn

215 how the evolving nature of disturbance events have the potential to create new forms of actor

216 relationships and decision making structures.

217

\section{3. Methods}

219 We performed a content analysis to examine the frequency with which the USFS is using

220 key terms relating to landscape resilience in planning, budgeting, and public relations

221 documents. All documents arepublically available on the Web. Content analysis is a systematic

222 and objective analysis of message characteristics and the method is widely used in social,

223 political, and communication sciences (Weber 1990,Neuendorf 2002). It consists of screening

224 any kind of document, such as articles, titles, or texts, and counting the frequency of occurrence

225 of key words, which can be grouped according to similarity in meaning. The content analysis

226 was interpretive (Neuendorf 2002), as we coded the key terms in their context to form groups of

227 conceptual categories.

228 We divided the methods for conducting the content analysis into two parts. The first

229 involved analyzing USFS Budget Justification reports for fiscal years 2006-2015 to examine the

230 change in the frequency of use of the following set of key terms:

231 - communityor communities

232 - landscape 
- landscape resilience or landscape resiliency

234 - resilience

235 - resilient landscape or resilient landscapes

236 The term "resilient landscapes" is a focal point in the President's Fiscal Year 2015 Proposed

237 Budget as described above, and was the centerpiece of our inquiry. However, we were interested 238 in how resilience was used in a SES context, so we included the term "communities" to examine 239 if social dimensions of forests were included in how resilience is being discussed. We also 240 included the term "landscape" in various forms because much of the SES literature pertaining to

241 resilience involves perspectives at the landscape scale, as is reflected in the use of "resilient

242 landscapes" in the USFS and beyond.

243 The Budget Justification reports were well suited for the first part of the analysis because

244 they are prepared annually, have a relatively standard format, and summarize the U.S. Forest

245 Service's yearly plans and objectives. The appropriations process, including Budget

246 Justifications, is in many ways critical to the USFS discursive cycle as it links together other

247 communication pieces used in generating and modifying plans, justifying and making budget

248 requests, and then implementing those actions outlined in the budget request. From the Budget

249 Justification reports, we recorded the total number of pages in the report, as well as the total

250 number of times each of the terms listed above was found in the report. We then calculated the

251 average frequency of each word group by dividing the number of times the words were used in a 252 given report by the number of pages in that report.

253 The second part of the analysis involved a Web search using the Forest Service's domain $254<$ fs.fed.us $>$ to locate USFS web pages and documents containing the terms "resilient landscape," 255 "resilient landscapes," "landscape resilience," or "landscape resiliency." Our document selection 
256 included public statements, budget justifications, budget overviews, research (i.e. articles, book

257 chapters and general technical reports), and planning initiatives. With regards to research related

258 documents, our study focused on those that are attainable through the USFS web pages and

259 therefore may not include some research articles that were coauthored by USFS employees. We

260 excluded web pages or documents in which these terms were found only as a citation of, or link

261 to, documents we had already analyzed, earlier drafts of documents we had already analyzed,

262 staff profiles, Statements of Proposed Action (SOPAs), and slide decks from presentations.

263 SOPAs were excluded because "resilience" was only included in project title lists without any

264 contextual information.In all cases, the content analysis noted what authorities within the USFS

265 are using these terms, to what audiences these terms are being presented, and the contexts in

266 which these terms are being applied.

\section{4. Results}

The web search was conducted on August 19, 2014, producing 124 documents. After

270 excluding certain documents for the reasons noted above, the search resulted in 111 documents,

271 not including the ten USFS Budget Justification reports for fiscal years 2006-2015.

\section{$273 \quad 4.1$ Frequency of Word Use over Time}

274 The first part of our analysis revealed that the use of the key terms has, for the most part,

275 increased steadily in USFS documents in the recent years (Figure 1). The terms "resilience" and

276 "resilient" have been present in all Budget Justification Reports for FY2006-2015, but their use

277 increased considerably in the FY 2011 Report, and has continued to increase since. The use of

278 "landscape(s)" also rosebeginning in FY 2011, and continued to increase steadily until the FY 
2792015 Report produced in 2014, when its frequency dropped below FY 2013 and FY2014 levels.

280 "Resilient landscape(s)" and "landscape resilience" first appeared in the Budget Justification

281 Report for FY 2012, and their use has slightly increased in subsequent reports. Similarly, the

282 terms "community" and "communities" began to increase in 2011.

283

284 Insert Figure 1 here

285

286 4.2 Documents Incorporating Resilience

287 For part two of the analysis, the documents and Web pages containing "resilience"ranged

288 from political statements and news releases (intended to be accessible to broad audiences) to

289 research articles, book chapters and general technical reports aimed at scientists and land

290 managers. Of the 111 documents containing these terms, five were undated, one was dated 1992,

291 seven were dated between 2002-2009, and 98 were dated between 2010-2014. We classified the

292 documents into the eleven categories shown (Table 1).

293

294 
Table 1. Classification of document types returned from Web search of key terms.

$$
\text { \# of } \quad \% \text { of }
$$

Document Type

Project, program, and research highlights*

Research articles, book chapters, and general technical reports

Public statements, news releases, and blog updates

Strategic plans, frameworks, and implementation documents

Newsletters and magazines

Budget justifications and budget overviews

Performance reports

Environmental impact statements and records and decision

Policy guidance
Documents

Total

26

25

17

15

9

7

6

3

3
$24 \%$

$23 \%$

$15 \%$

$14 \%$

$8 \%$

$6 \%$

$5 \%$

$3 \%$

$3 \%$

\section{TOTAL}

111

$100 \%$

*This includes Collaborative Forest Landscape Restoration Program communications

\subsection{Rise to Prominence}

Our analysis suggests that the Forest Service Manual (FSM) policy 2020 (78 FR 56202)

299 directive played a key role in the emergence of the term resilience in USFS discourse. This

300 interim directive wasput in place in 2008, was reissued several times, and proposed as permanent

301 policy in 2013. It was developed to provide parameters around the meaning of restoration to the

302 National Forest System lands and included discussion and definitions of restoration along with

303 related concept of resilience: 
"Restoration: The process of assisting the recovery of an ecosystem that has been degraded, damaged, or destroyed. Ecological restoration focuses on reestablishing the composition, structure, pattern, and ecological processes necessary to facilitate terrestrial and aquatic ecosystem sustainability, resilience, and health under current and future conditions. ${ }^{[\mathrm{Q} 1]}$

"Resilience: The capability of an ecosystem to endure disturbances and retain its structure and functions; the capacity of an ecosystem, which is subject to disturbance or

314 In an informal question and answer document associated with FSM 2020 (USFS 2008), the 315 Forest Service encouraged employees to develop an understanding of these terms and increase 316 their use in Forest Service planning documents and communications. change, to reorganize and renew itself. "[Q2]

\section{8}

In the years following the incorporation of the interim FSM 2020 directive, USDA Secretary Tom Vilsack and USFS Chief Tom Tidwell further promotedresilience by incorporating them into key statements. In 2009, Vilsack presented a National Vision for America's Forests in which he stated the following:

"Our shared vision begins with restoration. Restoration means managing forest lands first and foremost to protect our water resources, while making our forests more resilient to climate change." ${ }^{[\mathrm{Q} 3]}$

"The threats facing our forests don't recognize property boundaries. So, in developing a shared vision around forests, we must also be willing to look across property boundaries. 
In other words, we must operate at a landscape-scale by taking an 'all-lands approach'” (USDA 2009). ${ }^{[\mathrm{Q} 4]}$

329 Similarly, since 2010, USFS Chief Tom Tidwell's has promoted ecological restoration as a goal 330 for the United States to rally around, using his presentation and statements to advocate foran all331 lands approach that promotes restoration-related collaboration across jurisdictions, as well as to 332 present resilient landscapes as catalysts for job creation and the invigoration of rural economies 333 (Tidwell2010a, Tidwell 2010b, Tidwell 2010c, Tidwell 2011, Tidwell 2013a, Tidwell2013b). 334 The FLAME Act (2009) and associated Cohesive Strategy finalized in 2010 are also 335 potentially influential documents that have promulgated the use of resilience and related 336 terminology. These documents have established three primary national wildfire management 337 objectives, the first of which is "restoring and maintaining resilient landscapes"[Q5], increasing 338 the likelihood that USFS documents involving fire management include the term resilience if it is 339 to comply with the interagency objectives of the National Cohesive Strategy. Additionally, the 3402012 Forest Planning Rule, a document that provides a framework for land management plans 341 across the 155 national forests in the United States, mentions resilience as a management

342 objective. According to the rule's explanation, the rule was developed to address eight key

343 needs, the first of which is to "emphasize restoration of natural resources to make our NFS lands 344 more resilient to climate change, protect water resources, and improve forest health" (36 CFR 345 Part 219, 21164) $)^{[\mathrm{Q} 6]}$.

346 The above factors have likely worked in synergy to increase the prominence of the use of 347 resilience and related terminology within agency discourse. The USFS is promoting resilience as 348 a new restoration goal, and is advocating for restoration at the landscape scale. As such, 
349 resilience is being used with increased frequency by the USFS to describe restoration objectives

350 and research priorities.

$352 \quad 4.4$ SituatingResilience

353 The definition of resilience as provided in the Forest Service Manual (Q2) suggests that

354 the USFS is mostly concerned with ecological resilience given its attention to "the capability of 355 an ecosystem to endure disturbances and retain its structure and functions". This part of the 356 quote alludes to notions of withstanding shock while maintaining function, both central to this

357 form of resilience. Furthermore, the definition solely focuses on ecosystems, as it does not 358 pertain to the social dimensions of forests. However, the second half of this quote refers to the 359 characteristics described by social-ecological resilience: "the capacity of an ecosystem, which is 360 subject to disturbance or change, to reorganize and renew itself'. Collectively, the

361 termsreorganizeand renew are fundamental to the successful implementation of resilience in 362 social-ecological systems (Armitage et al. 2015), as they are invoked in the SES literature to 363 describe how social-ecological systems can adapt to change (Berkes et al. 2012). Further 364 complicating matters, the definition of resilience here is coupled with the preceding definition of 365 restoration (Q1), which speaks more to engineering resilience than the other two resilience 366 concepts. This quote mentions the need of restoration efforts to help ecosystems "recover", and 367 to "reestablish" forest conditions to a desired state; there is no mention of withstanding 368 disturbance or adapting to change. The lack of clarity regarding the use of resiliencein the Forest 369 Service Manual is important given the use of this document by USFS employees for 370 understanding the context in which to deliver policies. Stemming from this finding, our analysis 
371 below reveals that the ambiguity surrounding the use of resilience permeates several other

372 important USFS documents.

373 The use of engineering resilience was least observedin USFS documentation, yet applied

374 in one prominent example. The Forest Planning Rule - a document that provides a framework

375 for land management plans across the 155 national forests in the United States - discussed

376 engineering resilience when referring to restoration, stating:

377

"Plans will include plan components to maintain or restore ecological integrity, so that ecosystems can resist change, are resilient under changing conditions, and are able to

382 Here, the goal of restoration is to create resilient ecosystems that can resist change and recover

383 from disturbance. In this sense, resilience refers to the ability to minimize the occurrence of

384 disturbance and, if and when disturbance does occur, to allow a system to bounce back in an

385 effective manner, assumedly as quickly as possible. Furthermore, the term "maintain" speaks to

386 an objective focused on retaining an ecosystem state that is stable and predictable.

387 Similarly, other documentation describes a resilient landscape as one where natural

388 disturbance is managed. This is evident in the use of resilience in fire suppression policies where

389 the intent is to keep wildfire occurrence at a minimum:

391 "The Suppression Program is the primary source of funding for responding to wildfires

392 and helps restore and maintain resilient landscapes by managing naturally ignited, 
unplanned wildland fires on NFS lands to accomplish resource management, ecological

396 This quote can be interpreted as a subtle referencetowards engineering resilience in which the

397 use of fire suppression to restore and maintain resilient landscapes is achieved by controlling

398 disturbance. At the same time, this quote alludes to the USFS's use of fire as a management tool

399 for achieving resource objectives and promoting ecological benefits (Calkin et al. 2015), and as

400 such can be seen as a reference to ecological resilience. The latter interpretation is more likely to

401 be the case as our analysis reveals that the USFS most commonly adopts the concept of

402 ecological resilience, and that this adoption takes place most often in relation to landscape and

403 ecological restoration. Several strategic planning documents and research articles reflect the

404 trend towards this type of resilience by advocating for a departure from the strict use of

405 Historical Range of Variation (HRV) or Natural Range of Variability (NRV) as restoration

406 objectivesin favor of more "forward-looking" restoration strategies (e.g. Okanogan-Wenatchee

407 NF 2010, Hymanson and Collopy 2010, Stine et al. 2014). HRV and NRV have been used

408 interchangeably in USFS discourse to refer to "spatial and temporal variation in ecosystem

409 characteristics under historic disturbance regimes during a reference period" (78 FR 56202)

$410{ }^{[Q 9]}$. While previous studies have examined HRV and NRV as an approach for forest

411 management (Sharik et al. 2010), the FSM 2020 states, "the NRV is a tool for assessing

412 ecological integrity, and does not necessarily constitute a management target or desired

413 condition" (78 FR 56202) ${ }^{[\mathrm{Q} 10]}$. Furthermore, "[FSM 2020] broadens the definition of ecological

414 restoration beyond the traditional goal of reestablishing specific resource conditions that existed 
415 at some time in the past (such as those defined by historical range of variation, or HRV)" (USFS $4162008)^{[\mathrm{Q} 11]}$.

417 We identified a shift towards "future range of variability" (FRV)(Stine et al. 2014,

418 Okanogan-Wenatchee NF 2010)that engages in anecological resilience perspective with regards

419 to how ecosystems may absorb disturbance related to climate change (Gärtner et al. 2008). In

420 their 2010 Restoration Strategy, Okanogan-Wenatchee National Forest staff state that:

421

422

423

424

425

426

"By comparing current vegetation patterns to both historical and future reference conditions, managers will gain valuable insights into how systems have changed and how they are likely to change over time. Understanding these changes is the key to determining management strategies that provide for more sustainable and resilient forests" (Okanogan-Wenatchee NF 2010, 11). ${ }^{[\mathrm{Q} 12]}$

427

428 The USFS states that HRV is not a useful approach for the future management of forests because 429 climate change presents uncertainty in how historical vegetation structures and composition will 430 interact with future climate regimes. Furthermore, the discussion surrounding the movement 431 away from HRV emphasizes the importance of understanding how forest systems change over 432 time in order to create resilient forests.However, the quote does not address how FRV can 433 replace HRV given the uncertainty with understanding future climate conditions.

434 Concepts of ecological resilience are also called upon when discussing more recent 435 wildfire management strategies that focus on incorporating wildfire into the landscape rather 436 than employing contemporary suppression strategies. A century of fire suppression has created 437 characteristics that are increasingly beingdeemed undesirable, and that are calling for a return of 
438 fire processes in forest landscapes to improve landscape resilience (ACCG 2011, Luce et al. 439 2012, Ryan and Opperman 2013, Southwestern Crown Collaborative 2010, Tidwell 2013a, 440 USFS FAM N.D.). Examples of this language include:

441

"The last two decades have seen a paradigm shift from a suppression orientation to an acknowledgement of the need to use wildland fire as a whole-landscape management tool" (Luce et al. 2012, 50). ${ }^{\text {[Q13] }}$

"Ultimately, the safe reintroduction of fire in conjunction with sound wildfire management can substantially increase the area treated and the resilience of fire prone landscapes" (Ryan and Opperman 2013, 214) ${ }^{[\mathrm{Q} 14]}$

Observations of social resilience are relatively minimal in the context of USFS documentation, although those that appear are relatively recent, reflecting the upward trend in the use of the term "community" in overall documentation (see Figure 1). Some examples of social resilience do not explicitly describe how communities can become resilient, but instead discuss the social and economic wellbeing of communities in the context of resilient forests:

"Rural and urban communities depend on the forests for a variety of resources, commodities, and services, but for the rural communities in particular, national forest management can impact local economic and social conditions. With our many partners, the Forest Service is working to maintain the functions and processes characteristic of healthy, resilient forests and watersheds, and through delivery of our programs, maintain 
and enrich the social and economic environment of our local communities"

An example of social resilience that more strictly adheres to Folke's (2006)definition

465 isthe Pacific Northwest Research Station's General Technical Report titled Adaptations to

466 Climate Change: Colville and Okanogan-Wenatchee National Forests(Gaines et al. 2012). This

467 document includes a section titled "Increasing Social and Economic Resiliency to Climate

468 Change" which outlines objectives such as "[collaborating] to implement adaptive management

469 strategies. ${ }^{[\mathrm{Q} 16]}$ While the quote speaks to notions of social-ecological resilience by way of

470 adaptive management strategies, the overall document focuses on buffering communities from

471 the consequences of climate change in order for economic wellbeing to persist in the face of 472 change.

473 Social-ecological resilience is invoked most often in USFS documents in the context of

474 wildfire management by describing how communities and agencies can collectively manage

475 wildfire through action-based approaches in which communities, and even individuals, play an

476 active role in the creation and maintenance of resilience in fire-resilient landscapes. This occurs

477 in two ways. The first focuses on the resiliency of fire prone landscapes through the

478 reorganization of stakeholders that can collectively provide input into the forest management 479 process:

480

481 "At the national level, the USFS and BLM(Bureau of Land Management) are the two 482 largest land managers, with distinctly different areas of influence. Similarly, private 483 landowners, as a collective, control a majority of the land base across the country. 

as creating new partnerships is important in many areas to have an impact on the resiliency and management of the wildland fire landscape" (Cohesive Strategy 2014, 71). [Q16]

The second way is focused on the resilience of communities through prescribed burning.

491 pathways for change, and it is also restructuring the social organization and overall governance

492 of fire management by engaging and prioritizing community planning (Steelman and DuMond

493 2009). This is articulated here:

"Each member of a community can help prepare and protect against the threat of wildfire. From homeowner to land manager, business owner, and firefighter, everyone has a vital role. When communities embrace their individual roles, they increase their resiliency and become fire adapted" (Mowery and Prudhomme 2014, 9) ${ }^{[\mathrm{Q} 17]}$

501 adapted is used to describe that fire is part of the landscape, and different stakeholders with 502 varying responsibilities can collectively build an adaptive capacity towards the inevitability of

503 disturbance. While the focus here is on social resilience, the objective of fire adaptation suggests 504 that concepts of social-ecological resilience are being considered. 
"Through the programs we use to pursue landscape-scale restoration, we can sustain and create jobs, restore resilience to ecosystems, and enhance recreation infrastructure" $\left(\right.$ USFS 2012a, 6) ${ }^{[\mathrm{Q} 18]}$

512 Here, an ecosystem-based focus on restoration is explicitly integrated with social and economic 513 wellbeing. The degree to which related policies can incorporate how ecosystem and social 514 system functions influence each other across scales is not described, but this is one instance 515 where the goals applied to one part of the system are discussed in relation to another part.

\section{5.Discussion}

519 endurance, retention, reorganization, andrenewal (Q2). This definition aligns with resilience

520 definitions common in the SES literature,yet diverse messages characterize the actual uses of the

521 term resilience from resisting change to reorganizing social structures to adapt to disturbance.

522 This ambiguity is reflective of what some have identified as an inconsistent employment of

523 resilience in the land use policy and related literatures. Noted elsewhere, it may be that the value

524 of resilienceis that of a boundary object in so much as it provides a common language for

525 resource managers to communicate to each other using concepts that cross traditional

526 disciplinary boundaries (Brand and Jax 2007). Moreover, in budget justifications, speeches,

527 public relations documents and other political discourse, the ambiguity of these multiple

528 meanings can serve the political purpose of drawing support from diverse actors for a proposed

529 plan of action. However, with regards to land management objectives and priorities, the use of 
530 resiliencerequires conceptual clarity. As discussed above, the USFS both promotes and critiques

531 contemporary fire suppression practices in different documents as a way of building ecological

532 resilience at the landscape scale.Here too, resilience is posed in contrasting ways, from the

533 benefits of and need for fire suppression in order to resist disturbance on the one hand, versus the

534 desire to absorb fire in the landscape to be able to persist in the presence of disturbance.

535 While inconsistency in the use of resilience permeates USFS documentation in various

536 areas of the agency, our analysis revealed that the notion of engineering resilience appears

537 noticeably less than other resilience types, while the concept of ecological resilience is

538 increasingly embraced. The USFS primarily discusses ecological resilience via the

539 acknowledgement that resistance to disturbance has led to undesirable landscapes and that future

540 restoration efforts need to consider disturbance as part of the landscape. For example, the

541 discourse on fire suppression (e.g. Q13) practices are undergoing a "paradigm shift" as focus

542 moves away from suppression towards thinking about wildfire as a landscape management tool.

543 The idea here is for the landscape to experience disturbance in order to maintain its important

544 ecological functions and array of services. Meanwhile, social resilience receives relatively less

545 attention, and the focus is mainly on managing forests to maintain economic wellbeing. The

546 relatively minimal attention paid to social resilience is surprising given the disproportionate rise

547 in the use of the term community in USFS documents since 2010 (see Figure 1).

548 Social-ecological resilience and related conceptsare discussed mostly in the form of how

549 stakeholders should collectively consider forest management in order to adapt to disturbance.

550 However, while the USFS invokes various elements of social-economic resilience, the degree to

551 which their documents fully incorporate the various foci and contexts of social-ecological

552 resilience remains unclear. That is, the majority of documents focus on individual components of 
553 socio-ecological resilience, such as adaptation, the interplay between disturbance and

554 reorganization, and the desire to sustain important ecological and social systems. Our analysis

555 did not observe discussions of other social-ecological resilience concepts such as learning,

556 innovation, feedbacks and cross-scale interactions. In fact, most documents discussed all forms

557 of resilience only at the landscape scale. This seems to be the scale of inquiry in which resilience

558 concepts are being targeted by the USFS. An example is:

559

"Timber harvest is an important tool used to achieve multiple resource objectives and integrated with other activities including road decommissioning, stream restoration, and others helps to achieve the agency wide goal of increasing watershed health and improving resilience at the landscape level" (USFS2012b, 5-6) ${ }^{[\mathrm{Q} 19]}$

566 (Carpenter et al. 2001). Resilience is used primarily in the context of wildfire and climate

567 change, and to a lesser extent, in the contexts of pests, diseases, and human utilization of natural

568 resources. The continual threat of wildfire appears to have shaped the USFS's emphasis on

569 ecosystem restoration, and consequentially how resilience is considered. Even when the USFS

570 discusses the resilience of individuals, it is typically regarding resilience to wildfire (Q17).

571 Furthermore, specific forest goods (i.e. timber) are also discussed as needing to be resilient to 572 wildfire:

$574 \quad$ "Forests within the fire prone portions of the NWFP [Northwest Forest Plan area] are 575 also using thinning to improve the resiliency of timber stands as well as provide for the 
sustainability of northern spotted owl and other old growth dependent species." (Rey

There is also mention of needing to consider the resilience of forests to climate change,

580 but such cases are minimal and much less detailed than discussions on wildfire. The focus on a

581 single disturbance or source of shock in a system is what Folke et al. (2010) refer to as specified

582 resilience, which the authors caution against as placing too much emphasis on the resilience in

583 one part of the system could cause the system to compromise resilience in other ways (Carson

584 and Doyle 2000). For example, an overemphasis on resilience to wildfire could leave a forest

585 susceptible to other forms of disturbance such as invasive species as introducing more fire into a

586 landscape could potentially promote the introduction of non-native plants.

587

While conceptual clarity is needed to effectively guide a management paradigm based on

588 resilience, one has to considerwhether it is truly a new concept or simply "old wine in new

589 bottles". It can be argued that resilience is just the latest in a string of similar terms ranging from

590 "multiple use" to "new forestry" to "ecosystem management" to "adaptive management" that

591 have been put forward in policy documents over the past several decades only to fade from view.

592 "Multiple use forestry"dominated the USFS in the 1960s and was guided by the principle of

593 allowing simultaneous production of resources (timber, rangelands, water, wildlife and

594 recreation) based on sound planning practices. The principles of multi-use forests continue to

595 persist in the more recent dialogue around resilience that, as the opening quote of this paper

596 suggests, is concerned with healthy forests and other resources such as water, as well as

597 economic and societal prosperity. Similarly, "ecosystems management” focused on maintaining,

598 among other things, viable populations of native species and ecological process while 
599 accommodating human use of the ecosystem (Grumbine 1994). As was declared in 1992 by then

600 US Forest Chief F. Dale Robertson when the USFS became the first federal agency to adopt

601 ecosystem management, "an ecosystem approach will be used to achieve the multiple-use

602 management of the national forests and grasslands", and "we need to blend the needs of people

603 and environmental values in such a way that the national forests and grasslands represent

604 diverse, healthy, productive, and sustainable ecosystems" (Thomas 1996).

605 While there are key defining features that distinguish these paradigms and concepts from

606 one another, it is worth asking if nuanced discourse in the USFS over the years simply represents

607 persistent attempts to provide a more clear direction for implementing consistent core agency

608 values that are often left open to interpretation.Articulating values in a consistent fashion is

609 particularly difficult in agencies such as the Forest Service that are pushed and pulled by

610 continually evolving biophysical scientific concepts, the diversity of beliefs of individual

611 bureaucrats, multiple management and regulatory obligations, and the diversity of stakeholders.

612 In this context, obtaining conceptual clarity needed for on the ground management is quite

613 difficult and likely causes theForest Service to continually reframe concepts in order to be able

614 create the political space to act.

\section{6. Conclusion}

Resilience as a land usepolicy and management objective begs for conceptual clarity.

617 Resilience, as illustrated in the above analysis, is challenged by competing approaches that

618 areneither intentional nor defined. Resilience as a land use policy management objective will

619 require increasing specificity of resilience of what to what. This will require a shift from

620 specifying resilience of a specific resource or addressing a single problem. As illustrated in this

621 study, the use of resilience and associated key terms has become more prominent in the overall 
622 content of USFS documents. We found these terms increasingly used in public statements and

623 speeches by USFS leadership, as well as through research and general technical reports.

624 However, these types of communications have the least implication for on-the-ground

625 management. The USFS is using these terms least in planning, budget documents, and policy

626 guidance, perhaps because there remains conceptual uncertainty around these terms for them to

627 be effectively operationalized, implemented, and performance towards goals measured. It may

628 also be the case that resilience has not yet fully filtered down the management hierarchy to the

629 agencies responsible for land planning and implementation. The inconsistent nature of how

630 resilience is used by the USFS, as wells as the depth at which resilience concepts are

631 implemented, mirrors that of the SES literature where ambiguity remains regarding the meaning

632 of resilience and how it can be employed (Brand and Jax 2007). That this confusion permeates

633 federal agency discourse, especially in agencies that contain a substantial research component,

634 should not be unexpected, but remains an issue to be addressed and further explored if land use

635 policies employing the language of resilience are to be effectively designed and implemented. 


\section{Acknowledgements}

640 This material is based upon work supported by the National Science Foundation under Grant No.

6411414041 and by the United States Department of Agriculture under Grant No. 2011-67023-

64230695.

643 


\section{References}

645

646

647

648

649

650

651

652

653

654

655

656

657

658

659

660

661

662

663

664

665

666

667

668

669

670

671

672

673

674

675

676

677

678

679

680

681

682

683

684

685

686

36 CFR Part 219. http://www.fs.usda.gov/Internet/FSE_DOCUMENTS/stelprdb5362536.pdf. (September 30, 2014).

78 FR 56202.https:/www.federalregister.gov/articles/2013/09/12/2013-22149/ecologicalrestoration-policy. (September 30, 2014).

Adger, W.N. 2000. Social and ecological resilience: are they related? Progress in Human Geography.24, 347-364.

Adger, W.N., Brown, K., Nelson, D.R., Berkes, F., Eakin, H., Folke, C.,Galvin, K., Gunderson, L., Goulden, M. O'Brien, K., Ruitenbeek, J., Tompkins, E.L. 2011. Resilience implications of policy responses to climate change. Wiley Interdisciplinary Reviews: Climate Change. 2, 757766.

Amador-Calaveras Consensus Group [ACCG]. 2011. Collaborative forest landscape restoration program proposal: Amador-Calaveras Consensus Group cornerstone project.

http://www.fs.fed.us/restoration/documents/cflrp/2011Proposals/Region5/EldoradoStanislaus/A CCGCornerstoneCFLRAproposalfor2011.pdf. (September 30, 2014).

Anderies, J.M., Janssen, M.A., Ostrom, E. 2004. A framework to analyze the robustness of social-ecological systems from an institutional perspective.Ecology and Society.9, 18.

Armitage, D., Alexander, S., Andrachuk, M., Berdej, S., Dyck, T., Nayak, P.K., Pittman, J., Rathwell, K. 2015. Emerging concepts in adaptive management. In: Allen, C.R., Garmestani, A.S., (Eds.), Adaptive Management of Social-Ecological Systems. Springer, Netherlands, pp. 235-254.

Berkes, F., Doubleday, N.C., Cumming, G.S. 2012. Aldo Leopold's land health from a resilience point of view: self-renewal capacity of social-ecologicalsystems. EcoHealth. 9, 278-287.

Brand, F.S., Jax, K. 2007. Focusing the meaning(s) of resilience: resilience as a descriptive concept and a boundary object. Ecology and Society.12, 23.

Calkin, D. E., Thompson, M. P., \& Finney, M. A. 2015.Negative consequences of positive feedbacks in US wildfire management. Forest Ecosystems, 2, 1-10.

Carson, J., Doyle, J. 2000. Highly optimized tolerance: robustness and design in complex systems. Physical Review Letters.84, 2529-2532.

Carpenter, S., Walker, B., Anderies, J.M., Abel, N. 2001. From metaphor to measurement: resilience of what to what?. Ecosystems. 4, 765-781. 
Cumming, G.S., Olsson, P., Chapin III, F.S., Holling, C.S. 2013. Resilience, experimentation, and scale mismatches in social-ecological landscapes. Landscape Ecology. 28, 1139-1150.

Federal Land Assistance, Management, and Enhancement Act [FLAME Act]. 2009. http://www.fs.fed.us/aboutus/budget/requests/6751208_The\%20Fed\%20Land\%20Assistance\%2 0Mgmt\%20and\%20Enhancement\%20Act\%20of\%202009.pdf.(September 30, 2014).

Folke, C. 2006. Resilience: the emergence of a perspective for social-ecological systems analyses. Global Environmental Change. 16, 253-267.

Folke, C., Carpenter, S.R., Walker, B.,Scheffer, M., Chapin, T.,Rockström, J. 2010. Resilience thinking: integrating resilience, adaptability and transformability. Ecology and Society 15, 20.

Gaines, W.L., Peterson, D.W., Thomas, C.A., Harrod, R. J. 2012. Adaptations to climate change: Colville and Okanogan-Wenatchee National Forests. Gen. Tech. Rep. PNW-GTR-862.

Department of Agriculture, Forest Service, Pacific Northwest Research Station, Portland, OR. 34 p.

Gärtner, S., Reynolds, K.M., Hessburg, P.F., Hummel, S., Twery, M. 2008. Decision support for evaluating landscape departure and prioritizing forest management activities in a changing environment. Forest Ecology and Management. 256, 1666-1676.

Gunderson, L.H., Holling, C.S. 2002. Panarchy: Understanding Transformations in Human and Natural Systems. Island Press, Washington, D.C., 507 pp.

Hajer, M.A. 1995. The Politics of Environmental Discourse: Ecological Modernization and the Policy Process. Clarendon Press, Oxford, 332 pp.

Hirt, P. W. 1994. A Conspiracy of Optimism: Management of the National Forests Since World War Two. Lincoln, NE: University of Nebraska Press.

Holling, C.S. 1961. Principles of insect predation. Annual Review of Entomology. 6, 163-182.

Holling, C.S. 1973. Resilience and stability of ecological systems. Annual Review of Ecology and Systematics.4, 1-23.

Holling, C.S. 1996. Engineering resilience versus ecological resilience. In: Schulze, P. (Ed.), Engineering Within Ecological Constraints. National Academies Press, Washington, D.C., pp. $31-44$.

H.R.2647. https://www.congress.gov/bill/114th-congress/house-bill/2647.(August 3, 2015).

Hymanson, Z.P., Collopy, M.W., (Eds.). 2010. An integrated science plan for the Lake Tahoe basin: conceptual framework and research strategies. Gen. Tech. Rep. PSW-GTR-226. Department of Agriculture, Forest Service, Pacific Southwest Research Station, Albany, CA. 368 p. 
Luce, C., Morgan, P., Dwire, K., Isaak, D., Holden, Z., Rieman, B. 2012. Climate change, forests, fire, water, and fish: building resilient landscapes, streams, and managers.Gen. Tech. Rep. RMRS-GTR-290. Department of Agriculture, Forest Service, Rocky Mountain Research

Lloyd, M.G., Peel, D., Duck, R.W. 2013. Towards a social-ecological resilience framework for coastal planning. Land Use Policy. 30, 925-933.

MacKinnon, D., Derickson, K.D. 2013. From resilience to resourcefulness: a critique of resilience policy and activism.Progress In Human Geography.37, 253-270.

Manyena, S.B. 2006. The concept of resilience revisited. Disasters. 30, 434-450.

Moseley, C., Charnley, S. 2014. Understanding micro-processes of institutionalization: stewardship contracting and national forest management. Policy Sciences. 47, 69-98.

Mowery, M., Prudhomme, C. 2014. Proactive protection: a community-wide approach to wildfire preparedness. Fire Management Today: Being Prepared. 73, 9-

12.http://www.fs.fed.us/fire/fmt/fmt_pdfs/FMT73-3.pdf. (September 30, 2014).

National Cohesive Wildland Fire Management Strategy [Cohesive Strategy].2010. http:/www.fs.fed.us/sites/default/files/media/2014/25/cr-2010-ncwfmsecm6751208.pdf.(September 30, 2014).

The National Strategy: The Final Phase in the Development of the National Cohesive Wildland Fire Management Strategy [Cohesive Strategy]. 2014.

http://www.doi.gov/news/loader.cfm?csModule=security/getfile\&pageid=526008. (September $30,2014)$.

Nelson, D.R., Adger, W.N., Brown, K. 2007. Adaptation to environmental change: contributions of a resilience framework. Annual Review of Environment and Resources. 32, 395-419.

Neuendorf, K.A. 2002. The Content Analysis Guidebook.Sage Publications, Thousand Oaks, CA, $301 \mathrm{pp}$.

Okanogan-Wenatchee National Forest [Okanogan-Wenatchee NF]. 2010. The OkanoganWenatchee National Forest Restoration Strategy: adaptive ecosystem management to restore landscape resiliency.

http://www.fs.fed.us/rm/pubs/rmrs_gtr292/2010_okanogan_wenatcheee.pdf. (September 30, 2014). 
Ogden, L., Heynen, N., Oslender, U., West, P., Kassam, K.A., Robbins, P. 2013. Global assemblages, resilience, and earth stewardship in the anthropocene. Frontiers in Ecology and the

Ostrom, E., Janssen, M.A. 2005. Multi-level governance and resilience of social-ecological systems. In: Spoor, M. (Ed.), Globalisation, Poverty and Conflict. Springer, Netherlands.pp. 239259.

Rey, M. 2007. Forest restoration and hazardous fuels reduction efforts in Oregon and Washington. Statement before the Senate Committee On Energy and Natural Resources, Subcommittee On Public Lands and Forests, on December 13, 2007. http://www.fs.fed.us/sites/default/files/media/types/testimony/SENR_12-132007 Testimony.pdf. (September 30, 2014).

Ryan, K.C., Opperman, T.S. 2013. A national vegetation/fuels data base for use in fuels treatment, restoration, and suppression planning. Forest Ecology and Management. 294, 208216.

Sharik, T.L., Adair, W., Baker, F.A., Battaglia, M., Comfort, E.J., D’Amato, A.W., Delong, C., DeRose, R.J., Ducey, M.J., Harmon, M., Levy, L., Logan, J.A., O’Brien, J., Palik, B.J., Roberts, S.D., Rogers, P.C., Shinneman, D.J., Spies, T., Taylor, S.L., Woodall, C., Youngblood, A. 2010. Emerging themes in the ecology and management of North American forests. International Journal of Forestry Research.http://www.fs.fed.us/rm/pubs_other/rmrs_2010_sharik_t001.pdf. (September 30, 2014).

Schouten, M.A., Van Der Heide, C.M., Heijman, W.J., Opdam, P.F. 2012. A resilience-based policy evaluation framework: application to European rural development policies. Ecological Economics. 81, 165-175.

Smit, B., Wandel, J. 2006. Adaptation, adaptive capacity and vulnerability.Global Environmental Change. 16, 282-292.

Southwestern Crown Collaborative. 2010. Collaborative forest landscape restoration program proposal Southwestern crown of the continent landscape restoration strategy. http://www.fs.fed.us/restoration/documents/cflrp/2010Proposals/Region1/SWCrown/May_SW_ Crown_Landscape_Strategy_FINAL.pdf. (September 30, 2014).

Steelman, T.A., DuMond, M.E. 2009. Serving the common interest in U.S. forest policy: a case study of the Healthy Forests Restoration Act. Environmental Management. 43, 396-410.

Stine, P., Hessburg, P., Spies, T., Kramer, M., Fettig, C., Hansen, A., Lehmkuhl, J., O’Hara, K., Polivka, K., Singleton, P., Charnley, S., Merschel, A., White, R. 2014. The ecology and management of moist mixed-conifer forests in Eastern Oregon andWashington: a synthesis of the relevant biophysical science and implications for future land management. Gen. Tech. Rep. PNW-GTR-897. Department of Agriculture, Forest Service, Pacific Northwest Research Station, Portland, OR. 254 p. 
Tidwell, T. 2010a. A new environment for land and resource management: rising to the challenge. Presented at the Andrus Conference in Boise, ID, May 1, 2010. http://www.fs.fed.us/speeches/new-environment-land-and-resource-management-risingchallenge. (September 30, 2014).

Tidwell, T. 2010b.An agenda for conservation in the 21st century. Presented at the National Association of State Foresters in Orlando, FL, on September 18, 2010. http://www.fs.fed.us/speeches/agenda-conservation-21st-century. (September 30, 2014).

Tidwell, T.2010c.An all-lands approach to conservation. Presented at the Western States Land Commissioners Association in Little Rock, AR, on January 13, 2010. http://www.fs.fed.us/speeches/all-lands-approach-conservation. (September 30, 2014).

Tidwell, T. 2011. Meeting the forestry challenges of the future. Presented at the Forestry Policy Conference in Rhinelander, WI, October 17, 2011. http://www.fs.fed.us/speeches/meetingforestry-challenges-future. (September 30, 2014).

Tidwell, T. 2013a.Wildland fire management. Statement before the Committee On Energy and Natural Resources on June 4, 2013. http://www.fs.fed.us/sites/default/files/media/types/testimony/HAGC_2013-313for_mgt_rural_econ.pdf. (September 30, 2014).

Tidwell, T.2013b.National forest management and its impacts on rural economies and communities. Statement before the Committee On Agriculture, Subcommittee On Conservation, Energy And Forestry, United States House of Representatives, on March 13, 2013. http://www.fs.fed.us/sites/default/files/media/types/testimony/HAGC_20133-13for_mgt_rural_econ.pdf. (September 30, 2014).

Tilman, D., Downing, J.A. 1996. Biodiversity and stability in grasslands. In: Samson, F.B., Knopf, F.L. (Eds.), Ecosystem Management. Springer, New York, pp. 3-7.

United States Department of Agriculture [USDA]. 2009. Agriculture Secretary Vilsack presents national vision for America's forests.

http://www.usda.gov/wps/portal/usda/usdahome? contentidonly=true\&contentid=2009/08/0382.x ml. (September 30, 2014).

United States Forest Service [USFS]. 2008. Proposed directive: FSM 2020 - ecological restoration and resilience- questions and answers.

http://www.fs.fed.us/spf/tribalrelations/documents/policy/ecorestoration/Proposed_Directive_Q As_20090709.pdf. (September 30, 2014).

United States Forest Service [USFS].2011. Fiscal Year 2012 Budget Justification. http://www.fs.fed.us/aboutus/budget/2013/fy2013-justification.pdf. (September 30, 2014). 
869 United States Forest Service [USFS]. 2012a. Fiscal Year 2013 Budget Overview.

870 http://www.fs.fed.us/aboutus/budget/2013/fy2013-overview.pdf. (September 30, 2014).

871

872 United States Forest Service [USFS]. 2012b. Fiscal Year 2013 Budget Justification.

873 http://www.fs.fed.us/aboutus/budget/2013/fy2013-justification.pdf. (September 30, 2014).

874

875 United States Forest Service [USFS]. 2015. By the numbers. http://www.fs.fed.us/about-

876 agency/newsroom/by-the-numbers. (August 3, 2015).

877

878

United States Forest Service Fire and Aviation Management [USFS FAM]. N.D. Workforce and 879 development strategic

880 framework.http://www.fs.fed.us/fire/people/workforce_succession_planning/documents/fam_wo 881 rkforce_development_strategic_framework.pdf. (September 30, 2014).

882

Walker, B., Holling, C.S., Carpenter, S.R., Kinzig, A. 2004. Resilience, adaptability and transformability in social--ecological systems. Ecology and Society.9, 5.

892

893

Walker, B., Salt, D. 2006. Resilience Thinking: Sustaining Ecosystems and People in a Changing World. Island Press, Washington, D.C., 192 pp.

Weber, R.P. 1990. Basic Content Analysis.Sage Publications, Newberry Park, CA, 96 pp.

Wilson, G.A. 2013. Community resilience, policy corridors and the policy challenge. Land Use Policy. 31, 298-310. 


\section{List of Figures}

899

900

901 Figure 1. The average number of times key terms appeared per page in Budget Justification Reports from 9022006 to 2015.

903

904

905 


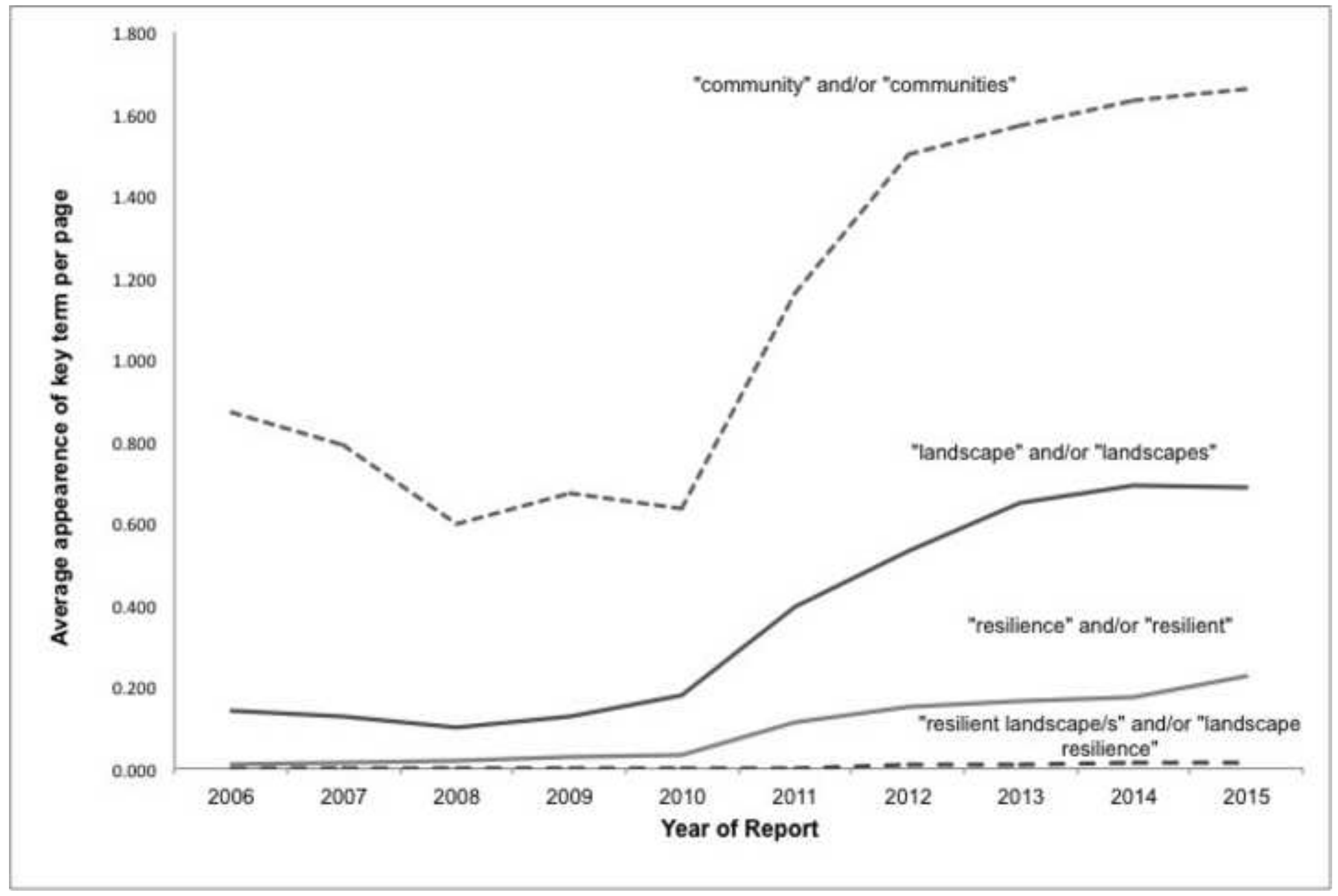

